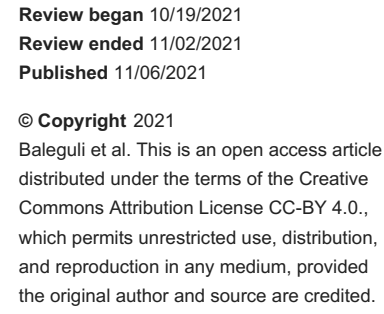

\title{
Human Herpesvirus 6 (HHV-6) Encephalitis in a Non-Transplant Patient With Polymyositis
}

\author{
Vidya Baleguli $^{1}$, Young Min Cho ${ }^{1}$, Jon Horn ${ }^{2}$, Addison Parris ${ }^{1}$ \\ 1. Internal Medicine, Northeast Georgia Medical Center, Gainesville, USA 2. Radiology, Northeast Georgia Medical \\ Center, Gainesville, USA
}

Corresponding author: Vidya Baleguli, vidya.baleguli@nghs.com

\begin{abstract}
Human herpesvirus 6 (HHV-6) was initially labeled as a human B lymphotropic virus because it was isolated in patients diagnosed with lymphoproliferative disorders. There are two variants of HHV-6: HHV-6A and HHV-6B. A considerable majority of recorded primary infections and reactivation events are primarily due to HHV-6B. We report a case of HHV-6 encephalitis reactivation in a 75-year-old Caucasian diabetic female with a past medical history of polymyositis treated with prednisone for a long time who presented with generalized weakness and drowsiness. She developed her symptoms after contact with her grandchildren, who recently had viral-like symptoms treated with antibiotics. Magnetic resonance imaging (MRI) of the brain without contrast showed $14 \mathrm{~mm}$ high transverse relaxation time (T2)/fluid-attenuated inversion recovery (FLAIR) signal intensity focus on the left temporal lobe, suspicious for primary versus metastatic neoplasm. Cerebrospinal fluid analysis found that protein concentration was $75 \mathrm{mg} / \mathrm{dl}$, glucose concentration $55 \mathrm{mg} / \mathrm{dl}$, white blood cell count was $22 / \mathrm{mm} 3$, with a lymphocytic predominance. Meningitis/encephalitis polymerase chain reaction (PCR) panel detected HHV-6. She was discharged after treatment with ganciclovir for 14 days. It is crucial to recognize HHV-6 infections in immunocompromised patients who present with a T2/FLAIR signal intensity focus in the left temporal lobe. In a hospital setting, rapid HHV-6 encephalitis testing is important to make a correct diagnosis to avoid any delay to prevent further morbidity and mortality.
\end{abstract}

Categories: Internal Medicine, Allergy/Immunology, Infectious Disease Keywords: hhv6, ganciclovir, pcr, reactivation, encephalitis

\section{Introduction}

Human herpesvirus 6 (HHV-6) was originally isolated in patients with a lymphoproliferative disorder, and it was labeled as a human B lymphotropic virus [1]. The two variants of HHV-6 are: HHV-6A and HHV-6B [2]. Most reported cases are from primary infections and reactivation due to HHV-6B.

HHV-6B infections are commonly described during the first three years of life during childhood. After primary infection, HHV-6B establishes latency like other herpes viral families. Roseola infantum, also known as exanthem subitum, is a well-known childhood disease caused by HHV6-B as a primary infection that resolves spontaneously. After the primary infection, the virus is known to replicate in the salivary glands and shed in the saliva. This is the recognized route of transmission for HHV-6 variant B strains. Subsequently, the virus remains latent in the monocytes and lymphocytes and endures in the tissues and cells at low levels. In adults, primary infection of HHV-6B is a rarely described entity [3].

Considering how rare the primary infection is in adults, most cases are considered to represent reactivation disease by HHV-6 [4]. In adults with HHV-6 seroconversion, mononucleosis-like symptoms with variable intensity and persistent lymphadenopathy have been described $[3,5,6]$. In rare instances, HHV-6 infection can be associated with different severity of encephalitis in immunocompetent patients. Clinical scenarios encountered can include alteration in mental status, seizures, psychosis, acute cerebellar ataxia, focal neurological signs, including but not limited to cranial nerve deficits or hemiparesis [7-10].

For treatment, foscarnet is known to be active against both HHV-6A and HHV-6B. On the other hand, ganciclovir is known to be active against HHV-6B, but some case reports described it as resistant to HHV-6A $[11,12]$. One study conducted in hematopoietic stem cell transplant recipients indicated that ganciclovir reasonably reduced HHV-6 in saliva compared with no therapy [13]. Even with these studies implying that specific antivirals may affect the replication of HHV-6, there have been no controlled clinical trials conducted to demonstrate such benefits in humans. Numerous circumstantial case reports and case series have advocated that there has been improvement in presumed HHV-6 encephalitis after treatment with either foscarnet or ganciclovir $[7,14,15]$. These conclusions require further validation in carefully controlled trials.

\section{Case Presentation}




\section{Cureus}

A 75-year-old Caucasian female with a past medical history of polymyositis on a maintenance dose of prednisone of $10 \mathrm{mg}$ daily, diabetes mellitus, status post right nephrectomy presented to the ED with complaints of generalized weakness and drowsiness. At baseline, the patient was minimally mobile due to active polymyositis. The patient was less responsive and confused with episodes of falling from her bedside commode. She denied having a cough, chest pain, shortness of breath, abdominal pain, nausea, vomiting, or diarrhea. In the last week, she had close contact with her grandchildren, who experienced a flu-like illness without rash treated with an antibiotic.

On physical examination, her vitals were significant for elevated blood pressure of $174 / 82 \mathrm{mmHg}$, the temperature of $37.1^{\circ} \mathrm{C}\left(98.7^{\circ} \mathrm{F}\right)$, respiratory rate of 16 breaths per minute. Bilateral lower extremity swelling was present. On neurological exam, she was alert but not oriented on the place and time. Her Glasgow Coma Score (GCS) was 13. The patient showed decreased consciousness level, slowly followed commands, and slurred speech. Her reflexes were diminished: $2 / 4$ in the bilateral biceps, triceps, brachioradialis, patellae, and Achilles. The rest of the exams were unremarkable without any focal neurological signs. Laboratory tests as noted in Table 1 . The hepatitis panel was negative, and blood cultures showed no growth at 120 hours.

\begin{tabular}{|c|c|c|}
\hline Laboratory Studies & Admission value & Reference Interval \\
\hline Sodium & $131 \mathrm{mEq} / \mathrm{L}$ & 135-145 mEq/L \\
\hline Potassium & $3.1 \mathrm{mEq} / \mathrm{L}$ & 3.6-5.2 mEq/L \\
\hline Blood urea nitrogen (BUN) & $71.0 \mathrm{mg} / \mathrm{dL}$ & $7-20 \mathrm{mg} / \mathrm{dL}$ \\
\hline Creatinine & $2.71 \mathrm{mg} / \mathrm{dL}$ & $0.74-1.35 \mathrm{mg} / \mathrm{dL}$ \\
\hline Estimated glomerular filtration rate (eGFR) & $16.1 \mathrm{~mL} / \mathrm{min} / 1.73 \mathrm{~m}^{\star} 2$ & $>90 \mathrm{mg} / \mathrm{mmol}$ \\
\hline Glucose & 306 mg/dL & $100-125 \mathrm{mg} / \mathrm{dl}$ \\
\hline Troponin 1 & 2.69 ng/mL & $0-0.4 \mathrm{ng} / \mathrm{mL}$ \\
\hline White blood cell (WBC) & $5.1 \mathrm{~K} / \mathrm{uL}$ & 4.5-11 K/uL \\
\hline Red blood cell (RBC) & 3.61M/uL & 4.7-6.1M/uL \\
\hline Hemoglobin & $9.8 \mathrm{~g} / \mathrm{dL}$ & $12-15.5 \mathrm{~g} / \mathrm{dL}$ \\
\hline Hematocrit & $31.4 \%$ & $36-48 \%$ \\
\hline
\end{tabular}

\section{TABLE 1: Laboratory results}

Computed tomography (CT) brain without contrast showed scattered white matter hypodensities, which were nonspecific but compatible with chronic microvascular ischemic disease.

Further ischemic workup was deferred due to acute kidney injury in the setting of chronic kidney disease (CKD) stage 4 . The patient had minimal responsiveness with a loop diuretic, and therefore she was started on hemodialysis for better volume management. MRI brain without contrast showed $14 \mathrm{~mm}$ high T2/fluidattenuated inversion recovery (FLAIR) signal intensity focus in the left temporal lobe, suspicious for primary versus metastatic neoplasm (Figure 1). The neurologist was consulted and recommended a follow-up assessment with a gadolinium-enhanced MRI of the brain. 


\section{Cureus}

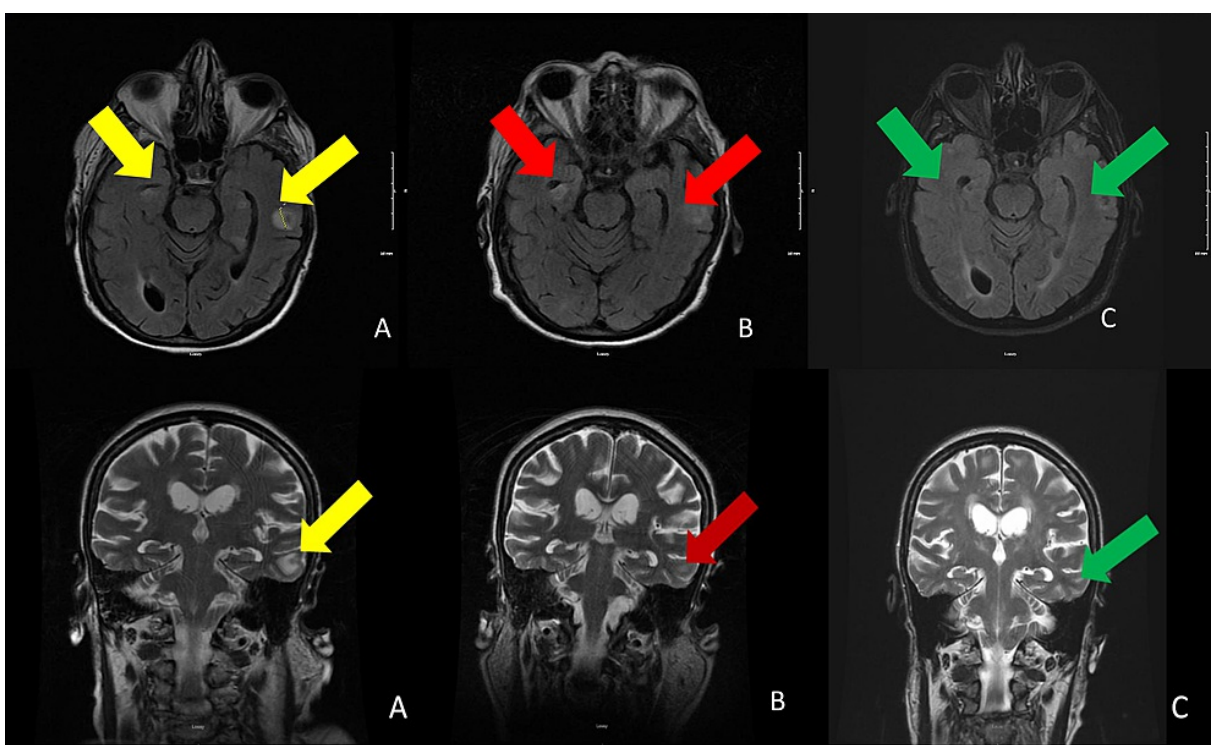

\section{FIGURE 1: MRI of the brain without contrast, axial and coronal views}

A. MRI of the brain without contrast, on day five of admission, showed in the left temporal lobe with T2/fluidattenuated inversion recovery (FLAIR) signal intensity $14 \mathrm{~mm}$ focus at the gray-white junction and right inferior temporal gyrus (yellow arrows)

B. MRI without contrast on day 30 shows the subtle increased intensity of the right inferior temporal gyrus and decrease intensity in the left temporal (red arrows).

C. MRI without contrast on day 176 shows improvement of the previous temporal and frontal enhancement (green arrows).

CT chest/abdomen/pelvis with intravenous (IV) contrast did not find any malignancy or metastatic disease. Given the cortical location of intracranial lesions, she was started prophylactically on levetiracetam $250 \mathrm{mg}$ daily. Electroencephalograms (EEG) showed generalized slowing and triphasic waves. MRI with contrast was deferred due to worsening kidney. With her history of chronic steroid therapy, a lumbar puncture (LP) was considered and showed protein $75 \mathrm{mg} / \mathrm{dL}$ (15-60 mg/dL), glucose $55 \mathrm{mg} / \mathrm{dL}$ (50-80 mg/dL), WBC 22/mm3 (0$8 / \mathrm{mm} 3), 7 \mathrm{RBC} / \mathrm{mm} 3$ (<1RBC/mm3), with a pleocytosis of lymphocytic predominance.

Meningitis/encephalitis polymerase chain reaction (PCR) panel detected HHV-6. The patient was started on acyclovir $530 \mathrm{mg}$ IV, and the infectious disease was consulted. Afterward, the patient was started on ganciclovir $75 \mathrm{mg}$ IV as an induction dose for 14 days as ganciclovir has been shown in studies to be active against HHV6. Serologic testing also revealed a positive IgG 1:40 (reference $<1: 10$ ) but negative IgM. Serum HHV-6 viral load was undetectable.

Repeat MRI brain without contrast after 14 days of treatment with ganciclovir showed chronic microvascular-type ischemic disease and some T2 shine through in the left frontal area (Figure 1). The location of abnormality seen in the left temporal region in the subcortical white matter was less prominent. By this time, there was a significant improvement in her mental status. She was not placed on prophylaxis because there was no clear indication due to her marked symptomatic improvement and resolution of the area of abnormality in the left temporal region on the MRI. The patient has been discharged with her home regimen of prednisone $10 \mathrm{mg}$ for polymyositis. Post-discharge at three-week outpatient follow-up, she was doing well without evidence of any further neurologic deterioration.

\section{Discussion}

Because HHV-6 is a common infection in childhood, most adults express antibodies to the virus. For diagnosis of encephalitis, pneumonitis, and acute clinical disorders, isolation of the HHV-6 or detection of HHV-6 DNA in cerebrospinal fluid, brain or lung tissue, and respiratory secretions is required. In presumed HHV-6 encephalitis patients, the common symptoms are delirium, ataxia, amnesia, confusion, and seizure [16]. The pathophysiology is not understood, but multiple studies suggested a systemic reactivation of HHV6 with high tropism for astrocytes in the hippocampus [17]. The typical MRI findings are hyperintensity on T2-weighted, FLAIR imaging, and diffusion-weighted imaging on bilateral medial temporal lobes, mainly affecting the hippocampus and amygdala [18]. However, MRI of the brain may be normal or demonstrate focal findings, such as augmentation in the temporal lobes [19].

There are no randomized controlled trials (RCT) showing the effectiveness of using antivirals to treat primary or viral reactivation caused by HHV-6. Several case reports have demonstrated successful treatment 
of HHV-6 associated encephalitis in bone marrow transplant recipients with either foscarnet or ganciclovir $[11-13,20]$. Unfortunately, there have been instances of reactivation and development of neurologic symptoms while these patients were receiving antiviral prophylaxis with these medications [14]. Despite this complication, due to the lack of other available therapies at present, it is reasonable to use one of these agents, alone or in combination, in immunocompromised patients with HHV 6 encephalitis. The existing data is less vibrant for the benefit of this therapy in immunocompetent patients, but treatment with one of these agents can be considered [14]. Numerous circumstantial case reports and case series have reported improvement in presumed HHV-6 encephalitis after treatment with either foscarnet or ganciclovir $[8,14,15]$. These conclusions require further validation in carefully controlled trials.

We suspect that infection in our patient may represent a reactivation due to chronic steroid exposure given her elevated IgG levels and negative IgM levels for HHV-6. HHV-6 viral load was likely not detected as levels were obtained following the initiation of ganciclovir. After 14 days of ganciclovir, the patient showed clinical and radiographic improvement, and we decided to hold the treatment and keep it in observation. She has been discharged on prednisone $10 \mathrm{mg}$ for frequent flare-ups of polymyositis. There is not enough data to keep on prophylactic antiviral treatment. Upon a three-week outpatient follow-up, the patient continued to exhibit no further signs of neurologic decline.

\section{Conclusions}

As a clinician, it is vital to recognize HHV-6 infections in immunocompromised patients with a T2/FLAIR signal intensity focus in the left temporal lobe. Although HSV encephalitis is more commonly associated with high signal intensity on T2-weighted and T2 FLAIR images on MRI, it is crucial to consider HHV-6 infections as differential because a delay in treatment can increase morbidity and mortality. We were able to establish a diagnosis by using the meningitis/encephalitis PCR panel. We believe that having an available test tool for HHV-6 is very important. The indication of prevention in the post-treatment course is still unclear, and we think further investigation is crucial.

\section{Additional Information \\ Disclosures}

Human subjects: Consent was obtained or waived by all participants in this study. Conflicts of interest: In compliance with the ICMJE uniform disclosure form, all authors declare the following: Payment/services info: All authors have declared that no financial support was received from any organization for the submitted work. Financial relationships: All authors have declared that they have no financial relationships at present or within the previous three years with any organizations that might have an interest in the submitted work. Other relationships: All authors have declared that there are no other relationships or activities that could appear to have influenced the submitted work.

\section{References}

1. Salahuddin SZ, Ablashi DV, Markham PD, et al.: Isolation of a new virus, HBLV, in patients with lymphoproliferative disorders. Science. 1986, 234:596-601. 10.1126/science.2876520

2. Ablashi DV, Salahuddin SZ, Josephs SF, et al.: HBLV (or HHV-6) in human cell lines. Nature. 1987, 329:207. 10.1038/329207a0

3. International Committee on Taxonomy of Viruses - Master Species List . (2020). Accessed: October 1, 2021: http://talk.ictvonline.org/files/ictv_documents/m/msl/4090.aspx.

4. Troy SB, Blackburn BG, Yeom K, Caulfield AK, Bhangoo MS, Montoya JG: Severe encephalomyelitis in an immunocompetent adult with chromosomally integrated human herpesvirus 6 and clinical response to treatment with foscarnet plus ganciclovir. Clin Infect Dis. 2008, 47 :e93-6. 10.1086/593315

5. Akashi K, Eizuru Y, Sumiyoshi Y, et al.: Brief report: severe infectious mononucleosis-like syndrome and primary human herpesvirus 6 infection in an adult. N Engl J Med. 1993, 329:168-71. 10.1056/NEJM199307153290304

6. Niederman J, Kaplan M, Liu CR, Brown N: Clinical and serological features of human herpesvirus-6 infection in three adults. Lancet. 1988, 332:817-819. 10.1016/s0140-6736(88)92783-3

7. Maric I, Bryant R, Abu-Asab M, et al.: Human herpesvirus-6-associated acute lymphadenitis in immunocompetent adults. Mod Pathol. 2004, 17:1427-33. 10.1038/modpathol.3800179

8. McCullers JA, Lakeman FD, Whitley RJ: Human herpesvirus 6 is associated with focal encephalitis . Clin Infect Dis. 1995, 21:571-6. 10.1093/clinids/21.3.571

9. Yao K, Honarmand S, Espinosa A, Akhyani N, Glaser C, Jacobson S: Detection of human herpesvirus-6 in cerebrospinal fluid of patients with encephalitis. Ann Neurol. 2009, 65:257-67. 10.1002/ana.21611

10. Hata A, Fujita M, Morishima T, Kumakura A, Hata D: Acute cerebellar ataxia associated with primary human herpesvirus-6 infection: a report of two cases. J Paediatr Child Health. 2008, 44:607-9. 10.1111/j.14401754.2008.01395.x

11. Deback C, Agbalika F, Scieux C, et al.: Detection of human herpesviruses HHV-6, HHV-7 and HHV-8 in whole blood by real-time PCR using the new CMV, HHV-6, 7, 8 R-gene kit. J Virol Methods. 2008, 149:28591. 10.1016/j.jviromet.2008.01.026

12. Engelmann I, Petzold DR, Kosinska A, Hepkema BG, Schulz TF, Heim A: Rapid quantitative PCR assays for the simultaneous detection of herpes simplex virus, varicella zoster virus, cytomegalovirus, Epstein-Barr virus, and human herpesvirus 6 DNA in blood and other clinical specimens. J Med Virol. 2008, 80:467-77. 10.1002/jmv. 21095 


\section{Cureus}

13. Ljungman P, Dahl H, Xu YH, Larsson K, Brytting M, Linde A: Effectiveness of ganciclovir against human herpesvirus-6 excreted in saliva in stem cell transplant recipients. Bone Marrow Transplant. 2007, 39:497-9. 10.1038/sj.bmt.1705617

14. Caserta MT, Hall CB, Schnabel K, et al.: Diagnostic assays for active infection with human herpesvirus 6 (HHV-6). J Clin Virol. 2010, 48:55-7. 10.1016/j.jcv.2010.02.007

15. Williams MV: Chapter 23 HHV-6: response to antiviral agents. Perspectives in Medical Virology. Ablashi DV, Krueger GRF, Salahuddin SZ (ed): Elsevier, Amsterdam; 1992. 4:317-335. 10.1016/S0168-7069(08)70074-0

16. Ogata M, Kikuchi H, Satou T, et al.: Human herpesvirus 6 DNA in plasma after allogeneic stem cell transplantation: incidence and clinical significance. J Infect Dis. 2006, 193:68-79. 10.1086/498531

17. Drobyski WR, Knox KK, Majewski D, Carrigan DR: Brief report: fatal encephalitis due to variant B human herpesvirus-6 infection in a bone marrow-transplant recipient. N Engl J Med. 1994, 330:1356-60. 10.1056/NEJM199405123301905

18. Zerr DM: Human herpesvirus 6 and central nervous system disease in hematopoietic cell transplantation . J Clin Virol. 2006, 37:S52-S56. 10.1016/S1386-6532(06)70012-9

19. Birnbaum T, Padovan CS, Sporer B, Rupprecht TA, Ausserer H, Jaeger G, Pfister HW: Severe meningoencephalitis caused by human herpesvirus 6 type B in an immunocompetent woman treated with ganciclovir. Clin Infect Dis. 2005, 40:887-9. 10.1086/427943

20. Canto CL, Sumita LM, Machado AF, Tateno A, Cunha EV, Machado CM: Optimization of the Sybr Green real time PCR for the detection of human herpes virus type 6 (HHV-6). Rev Inst Med Trop Sao Paulo. 2008, 50:61-63. 10.1590/S0036-46652008000100014 